\title{
Limites de gênero e presença feminina nos cursos superiores brasileiros do campo da computação*
}

\author{
Marcel Maggion Maia**
}

\section{Resumo}

O artigo discute a presença feminina nos cursos superiores brasileiros do campo da computação, a partir de dados do Censo de Ensino Superior/MEC. Entre 2000 e 2013, enquanto o número de concluintes homens cresceu $98 \%$, o de mulheres decresceu $8 \%$, constituindo um fenômeno raro no ensino superior brasileiro, mesmo quando comparado a campos masculinizados, como o da engenharia. $\mathrm{O}$ artigo apresenta, ainda, dados qualitativos que indicam a persistência de limites de gênero no campo estudado.

Palavras-chave: Relações de Gênero, Computação, Ensino Superior, Relações de Trabalho.

\footnotetext{
* Recebido para publicação em $1^{\circ}$ de outubro de 2015, aceito em 2 de dezembro de 2015.

** Mestrando do Programa de Pós-Graduação em Sociologia da FFLCH/USP, São Paulo, Brasil.marcel.maia@gmail.com
} 
224 Limites de gênero e presença feminina nos cursos superiores brasileiros...

Gender obstacles and the presence of women in Brazilian Computing graduate courses

\begin{abstract}
This article discusses the presence of women in computing graduation courses, based on official data. It reveals that, between 2000 and 2013, the number of male graduated students increased $98 \%$, while the number of female students decreased $8 \%$, constituting a rare phenomenon in the Brazilian graduation system, even when it is compared with traditionally male courses such as engineering. The article also presents some qualitative data related to the limitations that students and professionals of computer sciences have been stumbling upon in their carries.
\end{abstract}

Key Words: Gender Relations, Computing, Higher Education, Labor Relations. 
Embora a hierarquia entre os sexos já pudesse ser aferida antes dos anos 1980, é nessa década que a reprodução histórica das relações entre os sexos se torna um objeto propriamente sociológico, o que suscita uma série de investigações empíricas que apreendem a "relação social de sexo" como transversal ao edifício social (Hirata e Kergoat, 2008:43). Dessa forma, os posicionamentos conceituais iniciais do campo da sociologia, que remetiam a categorias biológicas de diferenciação "natural" entre os sexos, são superados pela construção conceitual relacional, que entende as categorias sexuais unidas por relações de poder e de dominação que se constroem e se modificam mutuamente.

A problematização da "divisão sexual do trabalho" se firma, assim, como conceito capaz de enfrentar os estudos sociológicos cegos às gritantes diferenças de experiências de trabalho vividas por homens e mulheres. Nos termos de Helena Hirata e Danièle Kergoat (2008:44):

Se definimos a relação social como uma tensão que atravessa o campo social, tensão que destaca alguns fenômenos sociais como centros em torno dos quais se constituem grupos com interesses antagônicos, chega-se à seguinte proposição: a divisão sexual do trabalho tem o status daquilo que está em jogo nas relações sociais de sexo. Assim temos, enfim, um paradigma sólido para incluir a diferença dos sexos na sociologia do trabalho.

Assim, duas categorias centrais ao conceito de divisão sexual do trabalho são introduzidas: o sexo enquanto construção social (gênero) e o trabalho doméstico. Ao mobilizar um conceito de trabalho mais amplo do que o do trabalho profissional, Kergoat (2002:50) observa dois princípios organizadores da divisão sexual do trabalho: o princípio da separação (homens e mulheres exercem trabalhos diferentes) e o princípio da hierarquização (o trabalho masculino vale mais do que o feminino). A divisão sexual do trabalho se caracteriza por manter as mulheres na esfera reprodutiva, enquanto que a esfera produtiva é designada aos homens, sendo os cargos de alto valor e prestígio prioritariamente 
226 Limites de gênero e presença feminina nos cursos superiores brasileiros...

designados aos últimos. A divisão sexual do trabalho pode, porém, assumir diferentes formas. Sua divisão não é estanque; pelo contrário, ela é permeável aos fenômenos sociais e, portanto, está sujeita às reproduções sociais desses fenômenos, bem como às rupturas que o tempo $e$ o espaço apresentam.

Dessa forma, um antigo conceito da sociologia do trabalho é questionado: o da qualificação. Ao se reconhecer que a qualificação é fundamentada no valor do trabalho, que, por sua vez, tem seu valor socialmente construído, é justo entender que as qualificações variam conforme essa relação. Dessa forma, as qualidades ditas "naturais" dos homens, tais como senso de competitividade, força e vontade de poder, são mais valorizadas socialmente do que aquelas atribuídas às mulheres, tais como construção de relacionamentos, delicadeza e sensibilidade. Ademais, as qualificações masculinas são caracterizadas por sua aquisição no meio social e vivência coletiva, enquanto que as qualificações femininas são apreendidas nos lares e construídas individualmente (Kergoat, 2002:51-52). Em um exemplo empírico, Hirata e Kergoat (2008:47) demonstram como, em uma empresa de biscuits as mulheres eram alocadas em linhas de embalagem com ritmo imposto, enquanto os homens experimentavam flexibilidade e trabalho em equipe.

$\mathrm{Se}$ as pesquisas ambientadas em fábricas tradicionais revelam práticas e processos de tal ordem, quando se focalizam setores econômicos que operam produtos que agregam mais tecnologia, o quadro não é muito diferente. Duas recentes pesquisas iluminam essa ideia. Ao pesquisar uma fábrica de aparelhos eletrônicos brasileira, Marcia Leite e Pilar Guimarães (2015) verificam que o trabalho das mulheres não vem sendo enriquecido com a introdução de novas tecnologias de informação e comunicação. Ao contrário, para as autoras, a organização da fábrica se dá de tal forma que os homens trabalham com novas tecnologias, enquanto as mulheres seguem em trabalhos manuais. Como colocam Leite e Guimarães (2015:359), "o produto de seu trabalho [das mulheres] é de alta tecnologia, mas o seu trabalho não". Também dedicada a uma indústria eletrônica, Thais Lapa 
(2014) observa a permanência da preferência por homens na promoção hierárquica, mesmo quando há mulheres mais qualificadas. Para Lapa (2014:169), "traduzem-se aí não somente uma divisão sexual do trabalho, mas também do poder (homens chefiam mulheres, com poucas exceções)". Debruçada sobre o setor de tecnologia da informação (TI), Bárbara Castro (2013:148) verifica que a divisão das funções passa pela orientação de gênero: as mulheres se concentram nas carreiras chamadas softs, menos ligadas à programação pura e mais à negociação, como a coordenação de projetos. A autora identifica, ainda, que as mulheres inseridas nas carreiras hard criam estratégias que buscam "apagar" suas características femininas, de forma a provarem sua capacidade técnica (Castro, 2013:155).

Os estudos feministas sobre o trabalho, afinal, fazem revelar que a distribuição dos postos não obedece de forma constante $e$ indiscriminada à qualificação, como a sociologia do trabalho universal e assexuada entendia originalmente. Desnudou-se, assim, como a qualificação opera como obstáculo à passagem do grupo social das mulheres ao mundo do trabalho construído coletivamente e amparado por mecanismos como a designação de guetos ocupacionais e a disparidade salarial.

\section{Bipolaridade do trabalho feminino}

No mercado de trabalho brasileiro feminino, observam-se continuidades e mudanças ao longo das últimas décadas do século XX. Hirata (2002) aponta que, simultaneamente ao desenvolvimento de profissões superiores do setor terciário, desenvolveram-se ocupações precárias ligadas ao care (cuidados com crianças, doentes, idosos etc.). Cristina Bruschini e Maria Rosa Lombardi (2000), com base em múltiplas fontes de dados secundários de caráter quantitativo, também observam dois polos de inserção das mulheres no mercado de trabalho: de um lado, expande-se o número de mulheres ocupadas em trabalhos de prestígio; de outro, um grande número de mulheres segue ocupado em trabalhos precários. 
228 Limites de gênero e presença feminina nos cursos superiores brasileiros...

$\mathrm{O}$ polo de trabalho feminino precário diz respeito às ocupações de baixo prestígio social, que exigem baixa qualificação profissional e têm baixo nível de proteção social. Sua persistência histórica é marcante: em 1998, cerca de 40\% da força de trabalho feminina encontrava-se em ocupações precárias (Bruschini e Lombardi, 2000:68). No Brasil, o exemplo mais acabado da divisão sexual dos trabalhos precários é o trabalho doméstico. Segundo o Instituto Brasileiro de Geografia e Estatística (IBGE, 2010:258-259), em 2009, 93\% das empregadas domésticas brasileiras eram mulheres, sendo que $73 \%$ delas não tinham carteira assinada. $O$ International Labour Office (ILO, 2013:124) registrava 6,7 milhões de mulheres ocupadas em empregos domésticos em 2009 no Brasil. ${ }^{1}$

O polo oposto diz respeito às profissões com alto prestígio social. Elas exigem nível educacional superior e até há pouco eram reservadas aos profissionais homens. É o caso da medicina, da arquitetura, do direito e da engenharia. Ao final do século XX, Lombardi e Bruschini (2000) observaram um incremento da presença de mulheres nesse polo. Segundo as autoras, entre os fatores que contribuíram para tal avanço se encontram os movimentos sociais e políticos ocorridos nas décadas de 1960 e 1970 - dentre eles, os feministas - e a expansão da escolaridade do público feminino.

Estariam as mulheres também mais presentes no setor de tecnologia da informação? A seguir, expõem-se a ascensão do setor econômico da TI, para, adiante, verificar-se como vem evoluindo a participação feminina em cursos superiores que pretendem formar profissionais nesse campo.

\section{Ascensão e consolidação do setor de TI no Brasil}

Ainda nos anos 1990, entre os atributos das organizações bem-sucedidas, elencava-se a capacidade de gerar conhecimento

\footnotetext{
1 Trata-se do maior contingente de trabalhadoras domésticas do mundo (Do total de 7,2 milhões trabalhadores, 504 mil são homens).
} 
e processar informações com eficiência $e$ a capacidade de transformar os meios de produção tão rapidamente quanto se mudavam os parâmetros culturais e tecnológicos. Com a ascensão das tecnologias da informação, nota-se uma série de transformações no âmbito do trabalho: novos mercados, como o do comércio eletrônico, emergem, novas profissões se consolidam e o gerenciamento empresarial se sofistica (Castells, 2011:225-229).

No Brasil, os serviços relacionados à computação e à internet, apesar de desenvolvidos mais tardiamente do que nos Estados Unidos, experimentaram gradual crescimento e, hoje, encontram-se consolidados. Como aponta a Pesquisa Anual de Serviços/IBGE 2 , a receita bruta da categoria "Tecnologia da Informação" cresce constantemente desde 2007; o número de pessoas ocupadas no setor desenha, igualmente, uma linha ascendente. ${ }^{3}$ Tomando um ângulo mais abrangente, no setor industrial, também observa-se ascensão, mas mais tímida: segundo a Associação Brasileira da Indústria Elétrica e Eletrônica (ABINEE, ago. 2014), o faturamento do setor de informática cresceu 7\% nos últimos três anos, somando 47 bilhões de reais em 2013. Por sua vez, o faturamento do setor eletroeletrônico cresceu $12 \%$ nos últimos três anos (somando 157 bilhões de reais em 2013). A receita bruta em TI e o número de ocupados em TI podem ser assim representados graficamente:

2 Tabela 2624 - Receita das empresas de serviços de informação e comunicação, total e empresas com 20 ou mais pessoas ocupadas, segundo as atividades CNAE 2.0 [http://www.sidra.ibge.gov.br/bda/pesquisas/pas/ - acesso em 02 dez 2014].

${ }^{3}$ O crescimento do pessoal ocupado é visível desde 2002. Até 2007, porém, a categoria utilizada pelo IBGE era a de "Atividades de Informática", o que impediu a exposição gráfica precisa da evolução histórica de todo o período. 
230 Limites de gênero e presença feminina nos cursos superiores brasileiros...

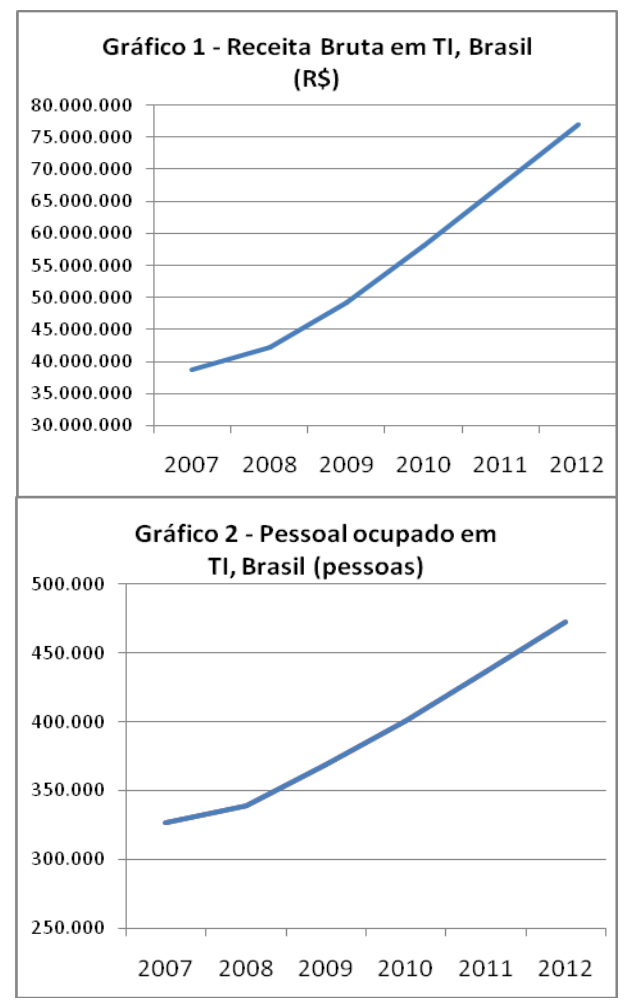

Fonte: IBGE.

Em consequência desse cenário, é razoável supor que o mercado de trabalho do setor tenha se aquecido. Segundo levantamento realizado pela Associação Brasileira de Empresas de Tecnologia da Informação e Comunicação (Brasscon), o ano de 2014 registrou um déficit de 45 mil profissionais no setor de TI no Brasil; os salários médios, por sua vez, cresceram $11 \%$ em relação a 2012 (Chaves, 2014). A partir desses dados, é plausível indicar uma tendência de crescimento da procura por cursos do campo da computação, como o de ciências da computação e o de sistemas de informação. Como se dá a distribuição dos sexos nesses cursos é a questão que se enfrenta a seguir. 


\section{O grupo das concluintes de cursos superiores do campo da computação}

Para a análise dos concluintes de cursos superiores, partiu-se dos dados do Censo de Ensino Superior fornecidos pelo Instituto Nacional de Estudos e Pesquisas Educacionais Anísio Teixeira, do Ministério da Educação (INEP/MEC). A partir da "área geral" definida pelo INEP como "ciências, matemática e computação" excluíram-se aquelas "classes" que não se relacionavam diretamente à atividade de computação. São elas: ciência atuarial, ciências, ciências ambientais e proteção ambiental, ciências biológicas, ciências da terra, estatística, física e astronomia, geografia, geologia, matemática e química. Também se excluiu a classe "uso do computador", que reúne os cursos "uso da internet" e "comércio eletrônico", como medida para que apenas cursos tradicionalmente reconhecidos no mercado $e$ de alto prestígio social fossem contabilizados. Pelo mesmo motivo, foram desconsideradas as graduações "a distância", "sequencial de formação específica" e "sequencial de complementação de estudos". Chegou-se, afinal, ao seguinte grupo de cursos doravante denominado "cursos do campo da computação". O período abordado, inicialmente, vai de 2000 a 2013. 
232 Limites de gênero e presença feminina nos cursos superiores brasileiros...

Tabela 1 - Cursos do campo da computação, segundo sexo do concluinte. Acumulado de 2000 a 2013, Brasil

\begin{tabular}{|c|c|c|c|c|c|}
\hline \multirow[t]{2}{*}{ Curso } & \multicolumn{2}{|c|}{ Masculino } & \multicolumn{2}{|c|}{ Feminino } & \multirow[t]{2}{*}{$\begin{array}{c}\text { Total } \\
\text { concluintes }\end{array}$} \\
\hline & $\begin{array}{c}\mathrm{N} . \\
\text { concluintes }\end{array}$ & $\%$ & $\begin{array}{c}\mathbf{N} . \\
\text { concluintes }\end{array}$ & $\%$ & \\
\hline Ciência da computação & 128.757 & 83 & 25.657 & 17 & 154.414 \\
\hline Sistemas de informação & 86.239 & 82 & 19.486 & 18 & 105.725 \\
\hline $\begin{array}{l}\text { Análise e Des. de Sistemas } \\
\text { (Tecnólogo) }\end{array}$ & 54.575 & 83 & 11.053 & 17 & 65.628 \\
\hline Administração de redes & 39.634 & 91 & 3.927 & 9 & 43.561 \\
\hline Processamento de dados & 30.981 & 77 & 9.435 & 23 & 40.416 \\
\hline Tecnologia em informática & 15.892 & 79 & 4.180 & 21 & 20.072 \\
\hline Análise de sistemas & 12.743 & 76 & 3.946 & 24 & 16.689 \\
\hline Tecnologia da informação & 7.249 & 78 & 2.036 & 22 & 9.285 \\
\hline $\begin{array}{l}\text { Informática (ciência da } \\
\text { computação) }\end{array}$ & 5.306 & 78 & 1.466 & 22 & 6.772 \\
\hline $\begin{array}{l}\text { Engenharia de } \\
\text { computação (hardware) }\end{array}$ & 3.191 & 87 & 467 & 13 & 3.658 \\
\hline Segurança da informação & 2.484 & 85 & 424 & 15 & 2.908 \\
\hline Banco de dados & 2.171 & 86 & 362 & 14 & 2.533 \\
\hline $\begin{array}{l}\text { Tecnologia em des. de } \\
\text { softwares }\end{array}$ & 1.944 & 87 & 287 & 13 & 2.231 \\
\hline Computação gráfica & 170 & 81 & 41 & 19 & 211 \\
\hline Informática educacional & 144 & 71 & 58 & 29 & 202 \\
\hline $\begin{array}{ll}\begin{array}{l}\text { Linguagens } \\
\text { programação }\end{array} & \mathrm{de} \\
\end{array}$ & 127 & 94 & 8 & 6 & 135 \\
\hline Sistemas operacionais & 104 & 80 & 26 & 20 & 130 \\
\hline Engenharia de softwares & 83 & 81 & 19 & 19 & 102 \\
\hline Robótica & 14 & 100 & 0 & 0 & 14 \\
\hline Total & 391.808 & 83 & 82.878 & 17 & 474.686 \\
\hline
\end{tabular}

Fonte: INEP

Diante da Tabela 1, constata-se que a presença feminina entre os concluintes de cursos do campo da computação é minoritária. De 2000 a 2013, apenas 17\% dos concluintes eram do sexo feminino. $\mathrm{O}$ acumulado do período, porém, não permite que um fenômeno raro no ensino superior brasileiro do século XXI seja devidamente exposto: o da queda da participação feminina em um campo do ensino superior. Por meio da série histórica dos cursos do campo da computação, verifica-se que, enquanto o número de concluintes homens cresceu $98 \%$ entre 2000 e 2013, o 
número de concluintes mulheres decresceu, sendo a taxa 20132000 de $-8 \%$. Conforme se vê nos gráficos 3 e 4 .
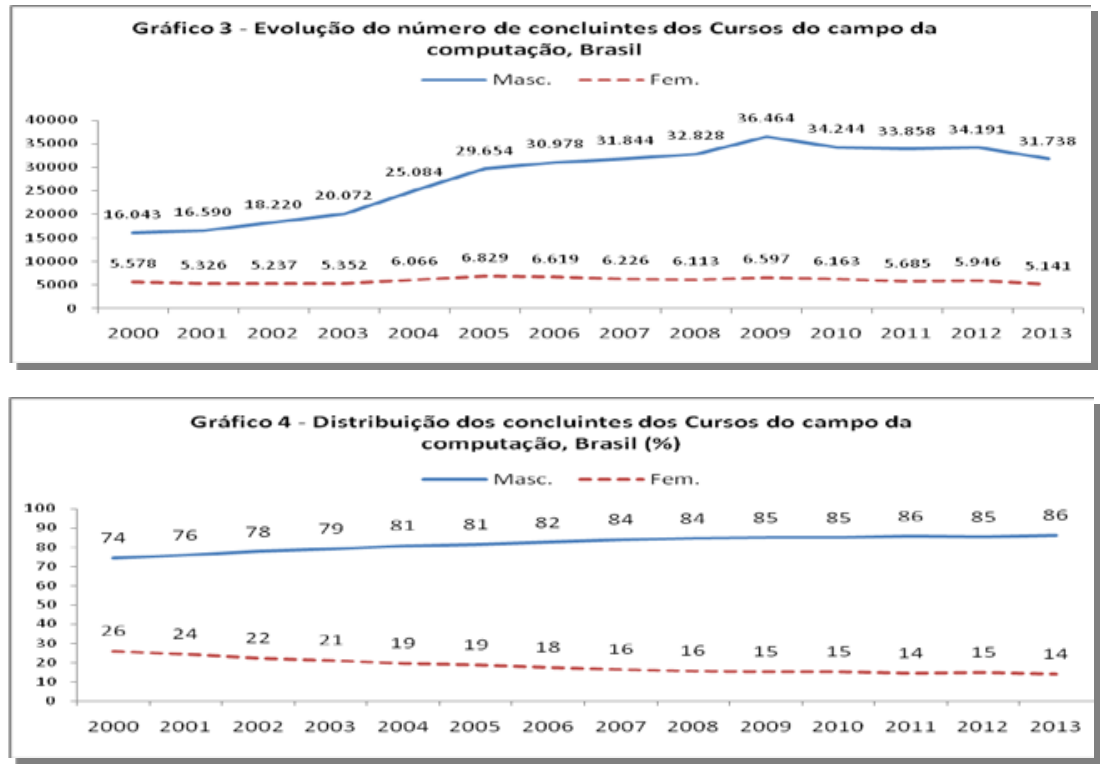

Fonte: INEP

Em um movimento diverso, no mesmo período, cursos de carreiras tradicionais como direito, engenharia, medicina $e$ arquitetura $^{4}$, experimentaram incremento no número de concluintes mulheres (exceto Direito, em 2013 ${ }^{5}$ ), conforme se verifica no gráfico 5 .

${ }^{4} \mathrm{Na}$ análise do Censo/INEP foram excluídos os cursos "arquitetura de interiores" e "paisagismo".

${ }^{5}$ Importante notar que o curso de direito exibe, em 2013, decréscimo, também, no número de concluintes homens. Vale registrar que, em 2013, o Censo de Ensino Superior registrou a primeira queda no total de graduandos desde 2004. Em nota à imprensa, o MEC afirmou que 97\% da queda se concentra em 14 instituições de ensino, e que a maioria dessas instituições passou por suspensão, redução de vagas ou descredenciamento (Vieira; Weber, 2014). 
234 Limites de gênero e presença feminina nos cursos superiores brasileiros...

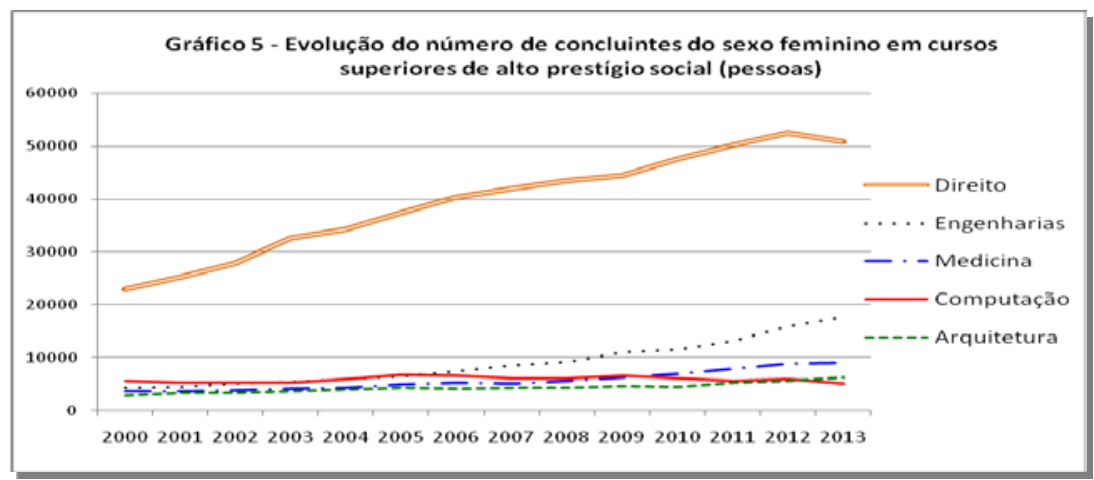

Fonte: INEP

Lombardi (2006a) demonstrou que, de 1985 a 2002, o equilíbrio entre os dois sexos em torno da divisão sexual do trabalho na engenharia vinha fortalecendo o grupo feminino. Segundo a autora, certos estereótipos de gênero que freavam a inserção das mulheres no mercado de trabalho da engenharia - $e$ mesmo a entrada das mulheres nessa área do conhecimento perderam seu poder de intimidação diante da série de questionamentos sociais a que foram expostos. Como se vê no Gráfico 5, recentemente, a inserção das mulheres na área do estudo da engenharia segue experimentado crescimento. Nos cursos do campo da computação, entretanto, verifica-se uma persistente sub-representação, o que sugere, afinal, que estereótipos vêm retendo a entrada de mulheres no campo.

Complementarmente, vejamos a evolução do curso com o maior número de concluintes no Brasil - o de ciências da computação - de forma isolada. Tomemos, ainda, um período histórico mais abrangente ${ }^{6}$ de forma a dirimir eventuais dúvidas quanto à persistência da sub-representação das mulheres em um campo do conhecimento notadamente caro à economia contemporânea.

6 Os dados referentes ao recorte em tela, disponibilizados pelo INEP, retrocedem a 1991. 

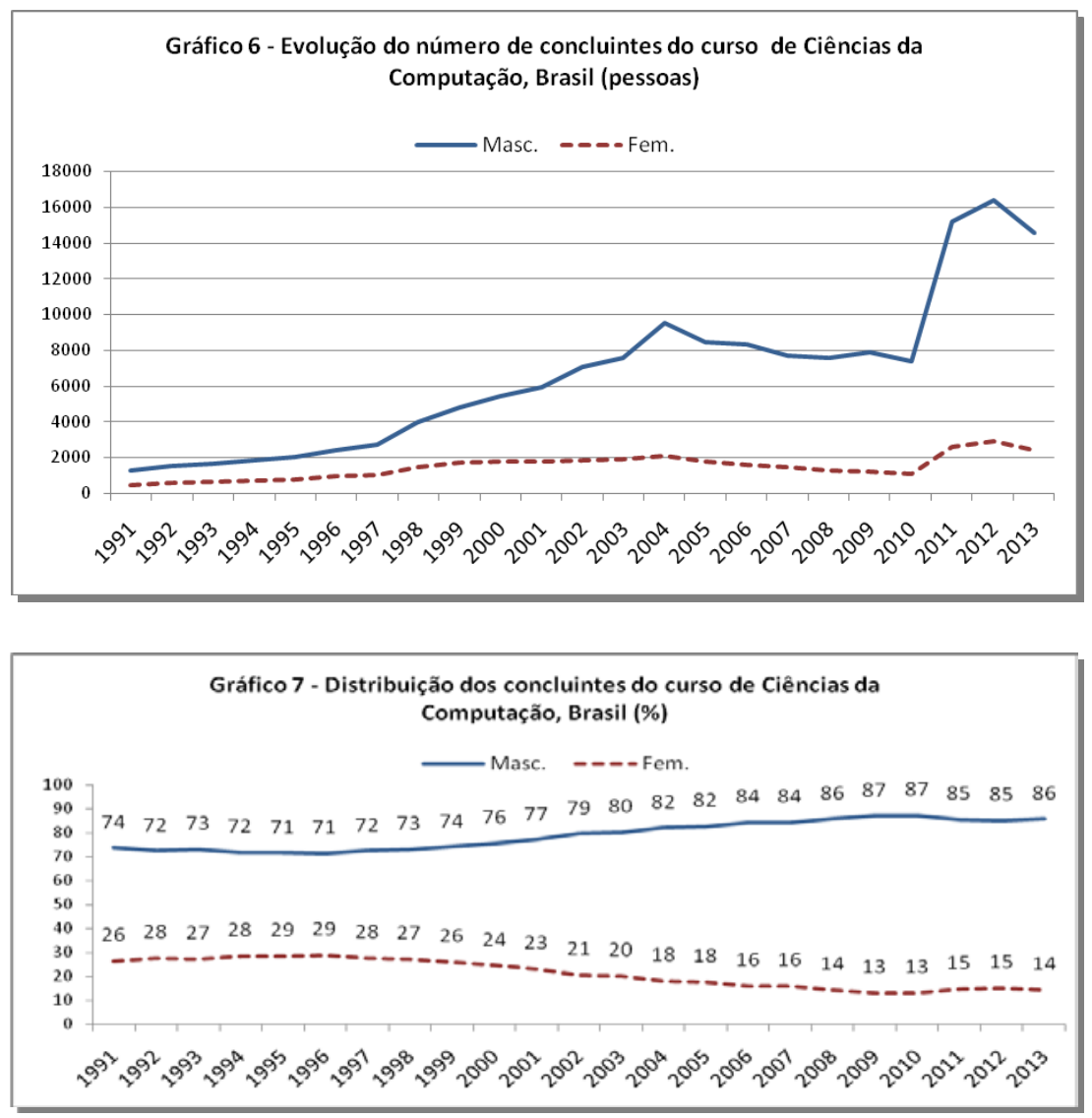

Fonte: INEP

A representação gráfica deixa claro que a categoria feminina apresenta uma evolução díspar da observada na masculina. No Gráfico 6, é possível notar que o número absoluto de mulheres se manteve baixo ao longo de todo o período em tela, enquanto que o número de homens exibe forte crescimento de 1998 a 2004, oscila entre 2005 e 2010, e cresce fortemente em 2011 e 2012. A maior sub-representação das mulheres nessa ciência, portanto, é observada nos anos mais recentes. No Gráfico 7, verifica-se que o número de concluintes do sexo feminino atinge seu pico relativo 
236 Limites de gênero e presença feminina nos cursos superiores brasileiros...

há 20 anos (29\% nos anos de 1995 e 1996), e que, desde então, o percentual de mulheres decresce com pequenas oscilações.

Que fatores sociais vêm freando a representação feminina em cursos do campo da computação, justamente em um período de ascensão econômica do setor? Com o objetivo de ilustrar o exposto, bem como de suscitar a construção de hipóteses para futuras pesquisas dedicas ao tema, apresentam-se, a seguir, alguns dados qualitativos de status indicativo.

\section{Limites de gênero nas trajetórias de concluintes de ciências da computação e profissionais de empresas de TI}

Foram capturados nove depoimentos de mulheres, sendo seis deles de graduadas em ciências da computação, pelo IME/USP, em diferentes anos ${ }^{7}$; e três depoimentos de gerentes em empresas de TI, não graduadas em exatas. ${ }^{8}$

Os papeis das mulheres inseridas no mercado de trabalho parecem previamente demarcados por dispositivos sociais que distinguem a qualificação feminina da masculina. Como se nota no depoimento de Flavia Tiné, uma das três mulheres de uma turma de 36 alunos graduada em 1990 no IME/USP: "Quando comecei a trabalhar, eram as mulheres [graduadas] que iam buscar o cafezinho. Eu me recusava: 'Só porque eu sou mulher?'”. Dilma da Silva reforça esse ponto: "Quando alguém desconhecido precisa de cópia, por algum motivo, pede para mim. Acontece que eu sou a líder do projeto". A cientista da computação e professora universitária Renata Wassermann enxerga a expressão de padrões de gênero rotineiramente. Diz ela: "quando digo minha profissão, dizem: 'Nossa, não parece!'”. Por sua vez, Luciana Caletti, cofundadora de uma start-up de tecnologia, em depoimento a Aguilhar (2014), diz:

7 Graduadas entre 1970 a 2010 no IME/USP. Os depoimentos públicos foram tomados durante o debate "Mulheres na Computação", promovido pelo Bacharelado em Ciências da Computação do IME/USP em set. 2014.

8 Os depoimentos públicos foram tomados durante o $3^{\circ}$ Congresso Nacional de Investimento Anjo, promovido pela Associação Anjos do Brasil em nov. 2014. 
Estive em um evento só para mulheres executivas e, na hora de apresentar o espaço do evento, o mestre de cerimônias comentou que no local havia também um shopping center, onde as mulheres poderiam fazer umas comprinhas depois do evento, como se esse fosse nosso único interesse.

Mariana Macario, gerente de relações governamentais do Google, releva uma situação similar:

Vejam bem, eu trabalho em uma empresa que tem esforços constantes [de inclusão das mulheres] (...) e uma pessoa falou pra mim: 'ter chefe mulher é fogo, porque mulher, conforme vai evoluindo na carreira, ela vai ficando mais dura e tal', aí falou o que já ouvimos muito 'mulher não tem como, ou ela fica mais dura ou não consegue'. O que me assusta não é a pessoa ter dito isso, porque já ouvi $n$ vezes, o que me chocou foi a pessoa sequer entender que ela estava falando isso para uma mulher.

O cenário de raridade feminina no setor parece colaborar para a continuidade da percepção estereotipada da mulher nos espaços de trabalho. A cientista da computação Claudia Melo, diretora da TOTVS, diz: "Quando eu passei a ocupar posições de liderança fui percebendo que o número de mulheres ficou rarefeito". Valéria de Paiva, pesquisadora de inteligência artificial nos Estados Unidos, por sua vez, afirma: "Já fui em conferência com 70 homens e eu. O cara que abriu a conferência disse: 'Gentlemen e Valéria'. E os números [de graduadas em computação] no Brasil estão caindo, em vez de melhorar. Isso não pode ser'".

A percepção dessas profissionais parece consoante aos dados organizados por Bruschini (2007). A autora observou que a parcela feminina em cargos de diretoria de serviços de 
238 Limites de gênero e presença feminina nos cursos superiores brasileiros...

informática ${ }^{9}$ era de $14 \%{ }^{10}$ em 2004 (Bruschini, 2007:557). Como vimos, a sub-representação das mulheres nos cursos superiores do campo da computação é nítida; tal escassez pode agravar a baixa representação feminina em postos elevados. Para a cientista da computação Silvia Goldman, graduada em 1981 no IME/USP, "muitas empresas têm programas de incentivo, mas não há candidatas mulheres, é um problema na base". Silvia Valadares, gerente de desenvolvimento da economia local de software da Microsoft, parece concordar com essa posição:

O problema de ter poucas mulheres em áreas de ciência $e$ tecnologia é o que faz que ainda tenham poucas mulheres empreendedoras nessas áreas, que tenham poucas start-ups lideradas por mulheres - está crescendo, mas são poucas -, então, o ambiente hostil talvez não seja nas empresas, necessariamente, talvez esteja no laboratório de ciências, esteja na engenharia para essas mulheres. O problema começa ali. A gente quer contratar, a Microsoft tem vagas abertas para mulheres de TI e não existem [candidatas]; temos dificuldade de encontrar, como temos dificuldade para encontrar negros em TI para trabalhar na Microsoft. Acho que o problema está - talvez de machismo - mais enraizado, não na empresa, mas na cultura brasileira.

Cabe apontar que as mulheres que ocupam cargos de liderança em empresas de TI parecem não escapar da desequilibrada carga de trabalho doméstico e de cuidado familiar que atravessa a divisão sexual do trabalho. A cientista Valéria de Paiva observa que "quando chega no pós-doutorado tá na hora de ter neném, [e] tem essa questão difícil para a mulher". Ana Fontes, fundadora da Rede Mulher Empreendedora e ex-

9 Segundo as famílias ocupacionais adotadas pela Classificação Brasileira de Ocupações (CBO 2002).

${ }^{10}$ Apenas em duas famílias ocupacionais de diretores se observam taxas menores: "Diretores de produção em empresas da indústria extrativa, transformação e de serviços de utilidade pública" $(10 \%)$ e "Diretores de obras em empresas de construção" (9\%). (RAIS/MTE, 2004 apud Brushini, 2007). 
executiva da Volkswagen, é enfática ao revelar práticas do mercado de trabalho de executivos:

No ano passado, eu tive três amigas minhas, em cargos de liderança executiva demitidas porque tiveram filhos pequenos. Então, infelizmente, as corporações ainda colocam uma letra escarlate na testa das mulheres, como se elas ficassem menos inteligentes quando têm filhos pequenos. (...) O ambiente corporativo se torna um pouco mais hostil, porque, quando você tem filhos pequenos, você precisa de uma palavrinha mágica que se chama flexibilidade.

Nota-se, afinal, que, embora o percentual de mulheres em cursos superiores do campo da computação limite a fração feminina nos postos de trabalho de TI, é na relação de gênero que tal limite efetivamente se expressa. Como os depoimentos deixam transparecer, os freios à ascensão feminina na carreira se dão no cotidiano dos espaços de trabalho, sob a forma de separação $e$ hierarquização da divisão sexual do trabalho.

Importante ressaltar, ainda, que os limites de gênero não passam a operar quando as mulheres se inserem no mercado de trabalho; eles se fazem presentes ainda na fase de treinamento, durante a graduação. O depoimento de Dilma da Silva, professora na Texas A\&M University, sobre seu período pré-vestibular, revela como o laço entre estereótipos profissionais e de gênero incide sobre a escolha da estudante do sexo feminino.

[Perguntavam-me:] 'Como uma aluna tão boa como você não vai para a medicina, não vai para a engenharia?'. 'Porque eu acho que eu gosto de matemática [eu dizia]' (...) É diferente você fazer vestibular para engenharia ou medicina, você tem toda a cultura social, nas escolas, nas famílias... Eu lembro que foi uma decisão pesada pra mim. A pressão era bem grande 'faz engenharia, porque engenharia que tem prestígio. 
240 Limites de gênero e presença feminina nos cursos superiores brasileiros...

O depoimento parece seguir a mesma linha do relato de uma estudante de computação, colhido por Saboya (2009:77):

Uma vez um professor colocou um exercício na lousa $e$ disse que era para "macho resolver", ou alguma coisa parecida. Eu terminei o exercício e levei para ele corrigir. Ele disse num tom de voz bem alto, para toda a sala ouvir: "Não acredito! É um absurdo! Uma mulher conseguiu resolver esse exercício".

Outro depoimento, esse de uma mãe estudante de computação, exemplifica a persistência da carga de trabalho de cuidado dos filhos ao longo de toda a trajetória feminina:

Exigem muito de mim no meu trabalho, confiam muito em mim e eu gosto do que faço. Estou tendo muitas dificuldades na faculdade, porque fiquei muito tempo afastada sem estudar. Tenho um filho de 10 anos e outro de sete. Tenho que estudar bastante nos finais de semana para poder acompanhar o desenvolvimento da matéria. O curso realmente é puxado. Meus filhos às vezes querem brincar comigo e eu não posso porque tenho que estudar e explico isso para eles, converso (...) Eles são bonzinhos e entendem, mas eu é que fico frustrada (Saboya, 2009:71).

Nota-se, afinal, importante similaridade entre os limites de gênero enfrentados pelas mulheres que perseguem graduação $e$ atuação profissional no campo da computação $e$ aqueles observados entre as engenheiras estudadas por Bruschini $e$ Lombardi (2000) e Lombardi (2006a, 2006b) na primeira década desse século.

\section{Considerações finais}

O artigo sustenta que, diante do aquecimento econômico do setor de serviços de computação e do crescimento da indústria de eletroeletrônicos, o número de concluintes de cursos do campo da computação cresceu, mas de forma desequilibrada segundo o 
sexo. No período de 2000 a 2013, enquanto o número de concluintes homens cresceu $98 \%$, o de concluintes mulheres decresceu $8 \%$, constituindo um fenômeno raro no ensino superior brasileiro, mesmo quando tomados campos de tradicional presença masculina, como o da engenharia.

O indicativo é de que os padrões de gênero presentes já na fase universitária vêm restringindo a representação das mulheres no mercado de trabalho do setor. Os depoimentos de profissionais inseridas no mercado de trabalho apontam que o acesso das mulheres qualificadas a postos de liderança é limitado por padrões de gênero operantes nos espaços de trabalho. A divisão sexual do trabalho se reproduz, também, ao se notar que estudantes $e$ trabalhadoras do campo da computação são sobrecarregadas por tarefas domésticas, especialmente, a de cuidado dos filhos. Podese, assim, indicar que a manifestação de estereótipos, discriminações e constrangimentos tem caráter contínuo, acompanhando toda a trajetória das profissionais. Os indicativos apresentados, afinal, vão ao encontro do que Lombardi (2013:130) chama de "teto de vidro" nas carreiras femininas de ciência $e$ tecnologia. Para a autora, ele é composto pela concentração da presença feminina em certas áreas, pela existência de preconceitos por parte da família e da sociedade, e pela falta de perspectiva no mercado de trabalho.

Complementarmente, cabe mencionar que a relação desequilibrada de forças na área da computação no Brasil vem sendo tema de debates e de iniciativas de grupos femininos, entre eles: o Prêmio Mulheres Tech em Sampa, da Rede Mulher Empreendedora, o grupo Mulheres Investidoras-anjo, o projeto Technovation Challenge Brasil; os blogs Mulheres, Tecnologia e Oportunidades e Mulheres na Computação, o grupo Rails Girls Brasil e outros. Vale destacar que, recentemente, diversas mulheres do campo da TI publicaram resposta (BRASILPOST, 16 jul. 2015) ao artigo de Demi Getschko, diretor-presidente do Núcleo de Informação e Coordenação do Ponto BR e Conselheiro do Comitê Gestor da Internet, publicado pelo O Estado de São Paulo. Para Getschko "buscar uma distribuição igual nas 
242 Limites de gênero e presença feminina nos cursos superiores brasileiros...

ocupações entre sexos é (...) errado e perigoso". Nota-se, entre seus argumentos, a prevalência do aspecto biológico: "sobrevivemos e evoluímos darwinianamente para nos tornarmos o que somos. Fatores culturais são importantes e é vital sua revisão cuidadosa, mas isso não passa por ignorar a biologia" (GETSCHKO, 12 jul. 2015). A opinião do conselheiro indica, afinal, que a superação dos limites de gênero aqui expostos não se restringem aos ambientes corporativos, sendo observados na instituição responsável por estabelecer as diretrizes estratégicas ao uso e ao desenvolvimento da Internet no Brasil.

\section{Referências bibliográficas}

ABINEE - Associação Brasileira da Indústria Elétrica e Eletrônica. Desempenho setorial ago. 2014. ABINEE, São Paulo, 2014. [http://www.abinee.org.br/abinee/decon/decon15.htm - acesso em: 02 dez. 2014].

AgUiLHAR, Lígia. Mulheres buscam mais espaço e diversidade no mercado de tecnologia. O Estado de São Paulo, 06 dez. 2014. [<http://blogs.estadao.com.br/link/mulheres-buscam-mais-espaco-ediversidade-no-mercado-de-tecnologia > - acesso em: 04 dez. 2014].

BRASILPOST. Viva a igualdade, com diversidade. Brasilpost, 16 jul. 2015. [http://www.brasilpost.com.br/coding-rights/viva-a-igualdade-comdive b 7813874.html - acesso em: 20 abr. 2015].

BRUSCHINI, Cristina; LOMBARDI, Maria Rosa. Bipolaridade do trabalho feminino no Brasil contemporâneo. Cadernos de Pesquisa $n^{\circ} 110$, São Paulo, Fundação Carlos Chagas, 2000, pp.67-104.

BRUSCHINI, Maria Cristina. Trabalho e gênero no Brasil nos últimos dez anos. Cadernos de Pesquisa vol.37, n¹32. São Paulo, Fundação Carlos Chagas, 2007, pp.537-572.

CAstells, Manuel. A Sociedade em rede. São Paulo, Paz e Terra, 2011 [1999].

CASTRO, Bárbara. Afogados em contratos - o impacto da flexibilizacãa do trabalho nas trajetórias dos profissionais de TI. Tese (Doutorado em Ciências Sociais) - IFCH/Unicamp, Campinas, 2013. 
CHAVES, Reinaldo. Faltam 45 mil profissionais de TI no Brasil. Folha de S. Paulo, 08 jun. 2014. [http://classificados.folha.uol.com.br/empregos/2014/06/1466085faltam-45-mil-profissionais-de-ti-no-brasil.shtml - acesso em: $02 \mathrm{dez}$ de 2014].

GeTSChKO, Demi. Viva a diferença! O Estado de São Paulo, 12 jul. 2015. [http://blogs.estadao.com.br/demi-getschko/viva-a-diferenca/ - acesso em: 20 abr./2015].

HIRATA, Helena. Reorganização da Produção e transformações do trabalho: uma nova divisão sexual? In: BRUSCHINI, Cristina; UnDEHAUM, Sandra G. (orgs.) Gênero, democracia e sociedade brasileira. São Paulo, FCC/Editora 34, 2002, pp.339-355.

HiRATA, Helena; KergOAT, Danièle. Paradigmas sociológicos revistos à luz da categoria de gênero: que renovação aporta a epistemologia do trabalho? Revista Novos Cadernos NAEA vol. 11, $\mathrm{n}^{\circ}$ 1, Belém, Núcleo de Altos Estudos Amazônicos/Universidade Federal do Pará, 2008, pp.39-50.

IBGE - Instituto Brasileiro de Geografia e Estatística. Síntese de Indicadores Sociais: uma análise das condições de vida da população brasileira, 2010. Estudos e pesquisas - Informação Demográfica e Socioeconômica n 27, Rio de Janeiro, IBGE, 2010.

ILO - International Labour Office. Domestic workers across the world: global and regional statistics and the extent of legal protection. Genebra, ILO, 2013.

KERGOAT, Danièle. A relação social de sexo: da reprodução das relações sociais à subversão. Pro-Posições vol.13, nº1 (37), Campinas, Faculdade de Educação da Unicamp, 2002, pp.47-59.

. Divisão sexual do trabalho e relações de sexo. In: HIRATA, Helena; LE DOARÉ, Hélène; SENOTIER, Danièle (coord.) Dictionnaire critique du féminisme. PUF, 2000, pp.35-44.

LAPA, Thaís. Processo de trabalho, divisão sexual do trabalho e práticas sociais das operárias na indústria eletroeletrônica no contexto da flexibilidade produtiva. Dissertação (Mestrado em Sociologia) FFLCH/USP, São Paulo, 2014. 
244 Limites de gênero e presença feminina nos cursos superiores brasileiros...

LeITE, Marcia de Paula; GuimarÃES, Pilar. Tudo muda, nada muda: as implicações do uso das tecnologias de informação sobre o trabalho das mulheres no setor eletroeletrônico. Cadernos Pagu (44), Campinas, Núcleo de Estudos de Gênero-Pagu/Unicamp, 2015, pp.333-366.

LOMBARDI, Maria Rosa. Engenheiras brasileiras: inserção e limites de gênero no campo profissional. Cadernos de Pesquisa n²127, São Paulo, Fundação Carlos Chagas, 2006a, pp.173-202.

. Engenheira \& gerente: desafios enfrentados por mulheres em posições de comando na área tecnológica. Tecnologia e Sociedade n³, Curitiba, Universidade Tecnológica Federal do Paraná, 2006b, pp.63-86.

LOMBARDI, Maria Rosa. Formação e docência em engenharia, na ótica do gênero: um balanço de estudos recentes e dos sentidos da feminização. In: YANNOULAS, Silvia Cristina (Coord.). Trabalhadoras Análise da Feminização das Profissões e Ocupações. Brasília, Editorial Abaré, 2013, pp.111-136.

SABOYA, Maria Clara. Alunas de engenharia elétrica e ciência da computação: estudar, inventar, resistir. Tese (Doutorado em Educação) - Faculdade de Educação/USP, São Paulo, 2009.

VIEIRA, Leonardo; WeBER, Demétrio. Censo do ensino superior mostra queda no número de formandos em faculdades brasileiras. O Globo, 09 set. 2014. [http://oglobo.globo.com/sociedade/educacao/censo-doensino-superior-mostra-queda-no-numero-de-formandos-emfaculdades-brasileiras-13879540 - acesso em: 02 dez de 2014]. 